\title{
Organizational water footprint: a methodological guidance
}

\author{
Silvia Forin ${ }^{1}\left[\right.$. Natalia Mikosch ${ }^{1} \cdot$ Markus Berger $^{1} \cdot$ Matthias Finkbeiner $^{1}$
}

Received: 12 September 2018 / Accepted: 23 July 2019/Published online: 28 August 2019

(C) The Author(s) 2019

\begin{abstract}
Purpose This paper proposes a practical methodological approach to assess the water footprint at the organizational level, in line with the current development of life-cycle based approaches toward the organizational scale on the one hand and footprint metrics on the other hand. This methodological development allows for organizational water footprint applications intended to inform management decisions and to alleviate water-related environmental impacts throughout the supply chain.

Methods ISO 14046, dedicated to water footprint with a major focus on products, and ISO/TS 14072 for organizational LCA (OLCA) are compared. A set of indications to carry out an organizational water footprint is identified based on: the requirements common to water footprint and organizational LCA; complementary methodological elements specified in only one of the standards; solutions to issues identified as conflicting. Additional application guidance on data collection prioritization for organizational water scarcity footprint studies is delivered based on the review of existing organizational case studies and comparative product or commodity studies.

Results and discussion O-LCA and water footprint provide complementary requirements for the scoping phase and the inventory and impact assessment phase respectively, according to the different methodological foci. We identify conflicting or contradictory requirements related to (i) comparisons, (ii) system boundary definition, and (iii) approaches to avoid allocation. We recommend (i) avoiding comparisons in organizational water footprint studies, (ii) defining two-dimensional system boundaries ("life-cycle dimension" and "organizational dimension"), and (iii) avoiding system expansion. Additionally, when carrying out a water scarcity footprint for organizations, we suggest prioritizing data collection for direct activities, freshwater extraction and discharge, purchased energy, metals, agricultural products and biofuels, and, if water or energy consuming, the use phase.

Conclusions The standards comparison allowed compiling a set of requirements for organizational water footprints. Combined with the targeted guidance to facilitate data collection for water scarcity footprint studies, this work can facilitate assessing the water footprint of organizations throughout their supply chains.
\end{abstract}

Keywords Corporate footprints · Data collection prioritization - Organizational LCA · Organizational water footprint $\cdot$ Supply chain management $\cdot$ Water footprint $\cdot$ Water scarcity

\section{Introduction}

In the last years, LCA applications and method refinement have developed toward larger scales, like organizations and countries. Methodological requirements for an ISOconform life cycle assessment of organizations is available

Responsible editor: Julia Martínez-Blanco

Silvia Forin

silvia.forin@tu-berlin.de

1 Department of Environmental Technology, Chair of Sustainable Engineering, Technische Universität Berlin, Office Z1, Strasse des 17. Juni 135,10623 Berlin, Germany
(ISO 2014b) and has been specified in both EU and UN context by dedicated guidance documents (European Commission 2012; UNEP 2015; Martínez-Blanco et al. 2019). The organizational level has been explored also in case studies for the packaging sector (Manzardo et al. 2016, 2018b), the construction sector (Neppach et al. 2017), the university sector (Lo-Iacono-Ferreira et al. 2016), the gastronomy sector (Jungbluth et al. 2016), a special purpose entity (Manzardo et al. 2018a), and 12 diverse organizations that road-tested the Guidance on Organizational Life Cycle Assessment (UN Environment 2017; de Camargo et al. 2019). An even further upscaling of the LCA method has been performed by territorial LCA, intended for informing land planning decisions (Loiseau et al. 2013, 2014, 2018; Mazzi et al. 2017). 
Besides the scales shift, a significant development of lifecycle based approaches observed in the last decade is the "footprint trend". Beginning with carbon footprint (Wiedmann and Minx 2007; ISO 2013a), several single environmental issue approaches following the life-cycle perspective have been developed and applied (Fang et al. 2014), fostered by easier communicability to a non-expert public. On the other hand, footprints are viewed by LCA experts with reservations, as they do not comply with the multi-impact principle of LCA (Finkbeiner 2009). In fact, the comprehensiveness aim of footprints is referred to a specific field. For example, the principle of comprehensiveness for a water footprint assessment according to ISO 14046 (ISO 2014a) requires considering "all environmentally relevant attributes or aspects of natural environment, human health and resources related to water, including water availability $[. .$.$] and water degradation$ [...]". In line with the developments in the LCA field, also footprints (within and beyond the LCA framework) were upscaled to the macroeconomic level (Hertwich and Peters 2009; Wiedmann et al. 2015) and to the organizational level, e.g., through ISO 14064 (ISO 2006b, 2013b) or the Greenhouse Gas Protocol (WBCSD/WRI 2004).

Within the ISO framework, organizations are included as object of water footprint studies in ISO 14046 (ISO 2014a), which provides an annex devoted to applying water footprint on the organizational level. Also, the Water Footprint Network foresees the application of comprehensive assessments of water consumption and degradation to companies (Hoekstra 2011), along with other initiatives such as the CDP Water Program, the Global Water Tool, and the Water Risk Filter (see (Forin et al. 2018) for a complete list and review).

In the case of water related assessments, the focus on organizations presents decisive advantages for informing decision-making. This is particularly the case for nonagricultural sectors, in which upstream processes such as energy and material extraction are responsible for the greatest amount of potential water-related impacts. This emerges from product case studies on technological products such as cars and flow regulators (Berger et al. 2012, 2017), from commodity-related studies (e.g., Buxmann et al. (2016) on primary aluminum) and from the waterrelated impact category results in the limited range of available case studies on organizational LCA. Among the banknotes-related activities performed by the Mexican Central Bank Banco de México, for example, upstream activities such as the production and transformation of raw materials (cotton and polymer substrate) are the main contributors to the water-related impact categories; the same applies for the oil producer Thanakorn Vegetable Oil Products based in Thailand (UN Environment 2017). Also organizational studies in the service sector show a dominance of upstream activities in water-related impact categories (see the Faculty of Science and Technology at UPH and the recycling NGO Emmaüs Europe (UN Environment 2017)). In other sectors, the downstream supply chain is particularly relevant: in case studies for the toiletry sector (de Camargo et al. 2019) and a special purpose entity created to build a tourist village (Manzardo et al. 2018a) the use phase has been found to have the highest relevance for water-related impacts.

In such cases, water-related impact reduction measures would require interventions at supply-chain level, which imply managerial decisions, since they regard the interplay between the organizations' environmental sustainability on the one hand and purchase decisions or product design on the other hand. Recent literature has shown that, in an organization with different product lines, basing decisions solely on the information delivered by a product case study might even increase overall environmental burdens (see, e.g., the concept of production allocation burden suggested by Manzardo et al. (2018b)). In other cases, a product case study might indicate a relative hotspot that is not significant at organizational level, thus directing investments to mitigation measures that would not be classified as the most urgent ones if the company as a whole was considered. Before this backdrop, management decisions seem to be easier to take if a complete picture of the organization and its suppliers is available. Despite the advantages of assessing water footprint at the organizational level, no stand-alone assessments for organizations going beyond the inventory level are available so far.

One reason might be the absence of a consistent guidance document for this specific application, which is indeed recognized, but not specifically addressed, in ISO 14046 and ISO/TS 14072 (see Sect. 2). Given the urgency of water-related environmental problems such as the water scarcity and acute water quality alteration in certain world regions, we aim at encouraging the application of water footprint for organizations by providing methodological guidance.

This paper leads practitioners through the methodological elements of organizational water footprint. For each of the four LCA phases, the requirements set by ISO 14046 (water footprint) and ISO/TS 14072 (organizational LCA) are compared and focused recommendations to prioritize data collection are provided. Section 2 explains how the comparison is operationalized and how recommendations for data collection are derived. Section 3 provides, for each LCA phase, the resulting requirements for organizational water footprint after discussing conflicting or contradictory elements. In Sect. 4, additional guidance for method application is provided for the specific case of water scarcity footprints, based on experience with organizational LCA and comparative product water footprint case studies. Finally, the main findings are discussed and conclusions are presented (Sects. 5 and 6 ). 


\section{Methods}

To develop an application guidance for organizational water footprint, two methods were applied. First, the requirements of ISO 14046 and ISO/TS 14072 were compared in order to identify corresponding, complementary, and conflicting requirements. This allowed developing a consistent set of guidelines to carry out an organizational water footprint study. This approach is described in Sect. 2.1. Further, the most relevant organizational activities for the specific case of water scarcity footprint studies are identified in order to help prioritizing data collection efforts. The related approach is described in Sect. 2.2.

\subsection{Comparison method}

The methodological scheme for organizational water footprint is based on the standards ISO 14046 ("Environmental Management - Water footprint - Principles, requirements and guidelines") (ISO 2014a) and ISO/TS 14072 ("Environmental management - Life Cycle Assessment Requirements and guidelines for organizational life cycle assessment") (ISO 2014b).

Both documents are based on ISO 14040 (ISO 2009) and ISO 14044 (ISO 2006a). ISO/TS 14072 specifies the adaptations needed when performing a life cycle assessment of organizations instead of products. Additional recommendations for applying organizational LCA are delivered by the "Guidance on Organizational Life Cycle Assessment," result of the UNEP/SETAC Life Cycle Initiative Flagship Activity LCA of Organizations (Martínez-Blanco et al. 2015; UNEP 2015), tested by 12 pilot organizations (UN Environment 2017; Martínez-Blanco et al. 2018).

ISO 14046, though based on ISO 14044, is a stand-alone standard and contains all necessary information to perform a water footprint study. Additionally, Annex A to ISO 14046 "Additional requirements and guidelines for organizations" explains the adaptations needed to carry out a water footprint study on the organizational level.

In other words, organizational LCA and water footprint, though both based on the milestone standards of life cycle assessment ISO 14040 and ISO 14044, have different foci, as highlighted in Fig. 1. Organizational LCA is a multiimpact method considering, among others, data related to water as elementary flow in the inventory analysis phase, and water-related impact categories in the impact assessment phase. Therefore, organizational water footprint can be considered as a subset of organizational LCA, such as a productrelated water footprint study can be performed as part of a multi-impact assessment considering also non-water-related indicators. On the other hand, water footprint as in ISO 14046 includes also organizations in its scope, although most methodological elements are conceived from a product perspective and focus on the data required to perform water- related impact assessment. In other words, organizational water footprint, though being included in both the organizational LCA and the water footprint framework, does not represent in either case the focus of the standard. In this way, practitioners taking product water footprint as starting point would lack specific guidance on organization-specific issues, like defining the organization to be studied and setting organizationspecific system boundary. The other way around, i.e., starting from organizational LCA, would imply lacking specific requirements for water-related impacts.

In order to profit from the different foci of organizational LCA and water footprint relevant to performing an organizational water footprint study, the requirements of ISO 14046 and ISO/TS $14072^{1}$ for each LCA phase are juxtaposed. We identify:

1. Methodological elements common to both organizational LCA and water footprint (overlaps, displayed in plain characters in Tables 1, 2, 3, 4, and 5) that can be directly integrated in the requirements for organizational water footprint (right column of each table);

2. Requirements or indications that overlap, but prove conflicting or contradictory, for which a specific choice is necessary (bold characters in Tables 1, 2, 3, 4, and 5). These issues are discussed in depth and recommendations on the most suitable application to organizational water footprints are delivered;

3. Requirements that are specific to either ISO 14046 or ISO/TS 14072, regarding issues specific either to water footprint or to organizations, but not conflicting with each other (displayed in italic characters in Tables 1, 2, 3, 4, and 5). These are integrated in the requirements for organizational water footprint.

The comparison results, i.e., the requirements for organizational water footprint, are displayed in the right column of Tables 1, 2, 3, 4, and 5 .

\subsection{Activity prioritization method}

To prioritize organizational activities as defined and explained in Sect. 4.1, a three-step approach was applied:

1. Existing organizational LCA case studies including water scarcity impact categories were examined to identify the activities which mainly contributed to the organization's water scarcity;

2. The contribution of the activities identified in step 1 was proofed by analyzing water consumption studies on the macroeconomic level. The aim was to prevent recommending high prioritization for activities that only

\footnotetext{
${ }^{1}$ complemented by the requirements of ISO 14044 if no organization-specific issues are mentioned in ISO/TS 14072
} 

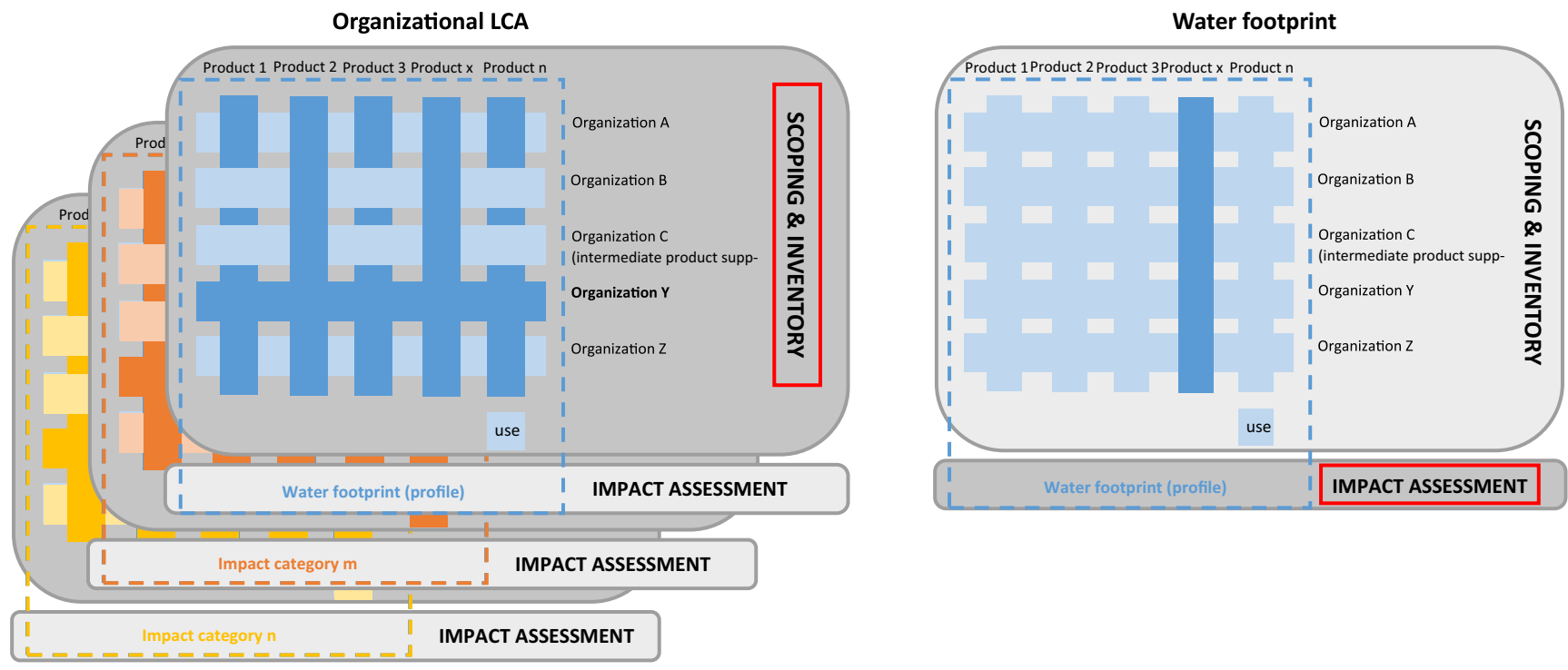

Fig. 1 Juxtaposition of the methodological structure and foci for organizational LCA and water footprint. Organizational LCA focuses on the organizational level (organization Y and its products' life cycles);

it adapts the scoping and inventory phase to organizations. Water footprint has products as main object; it lays the ground for waterspecific impact assessment. Adapted from Finkbeiner et al. (1998)

have a relative consistent weight in existing case studies, which, given the limited pool, could not be chosen representatively for different sectors;

3. Additional literature research (product-related case studies) was conducted to classify significant organizational activities which have not been considered separately in available organizational case studies, such as purchased fuels or waste management, or to explore technological products.

The results of steps 1 and 2 are illustrated in Table 6 and build the backbone for the activity prioritization in Sect. 4.2. The results of step 3 are directly inserted in Sect. 4.2.

\section{Comparing water footprint and organizational LCA}

\subsection{Goal and scope}

\subsubsection{Setting the goal}

Defining the goal of the study lays the ground for the study design and depends on which information the organization expects from the water footprint study. The requirements according to the water footprint and the organizational LCA method are summarized in Table 1.

While defining the goal, certain items need to be mentioned. Among them, the requirements of ISO 14046 and

Table 1 Indications and requirements for setting the goals of an organizational water footprint study. Comparisons between ISO/TS 14072 and ISO 14046 and recommendations for organizational water

footprint. (Potentially) conflicting requirements are highlighted in bold; requirements set by only one method are highlighted in italic

\begin{tabular}{|c|c|c|c|}
\hline Goal & $\begin{array}{l}\text { Organizational LCA } \\
\text { (ISO/TS 14072) }\end{array}$ & $\begin{array}{l}\text { Water footprint } \\
\text { (ISO 14046) }\end{array}$ & $\begin{array}{l}\text { Organizational water footprint } \\
\text { (recommended) }\end{array}$ \\
\hline \multirow{5}{*}{$\begin{array}{l}\text { Items to be } \\
\text { unambigu- } \\
\text { ously stated }\end{array}$} & Intended application & Intended application & Intended application \\
\hline & Reason for carrying out the study & Reason for carrying out the study & Reason for carrying out the study \\
\hline & Intended audience & Intended audience & Intended audience \\
\hline & \multirow[t]{2}{*}{$\begin{array}{l}\text { A statement that the results are not intended } \\
\text { to be used in comparative assertions } \\
\text { intended to be disclosed to the public }\end{array}$} & $\begin{array}{l}\text { Whether the study is part of a life } \\
\text { cycle assessment where a } \\
\text { comparative assertion is } \\
\text { intended }\end{array}$ & $\begin{array}{l}\text { A statement that the results are not intended } \\
\text { to be used in comparative assertions } \\
\text { intended to be disclosed to the public }\end{array}$ \\
\hline & & $\begin{array}{l}\text { Whether the study is a stand-alone } \\
\text { assessment or part of a life cycle } \\
\text { assessment }\end{array}$ & $\begin{array}{l}\text { Whether the study is a stand-alone assess- } \\
\text { ment or part of a life cycle assessment }\end{array}$ \\
\hline
\end{tabular}




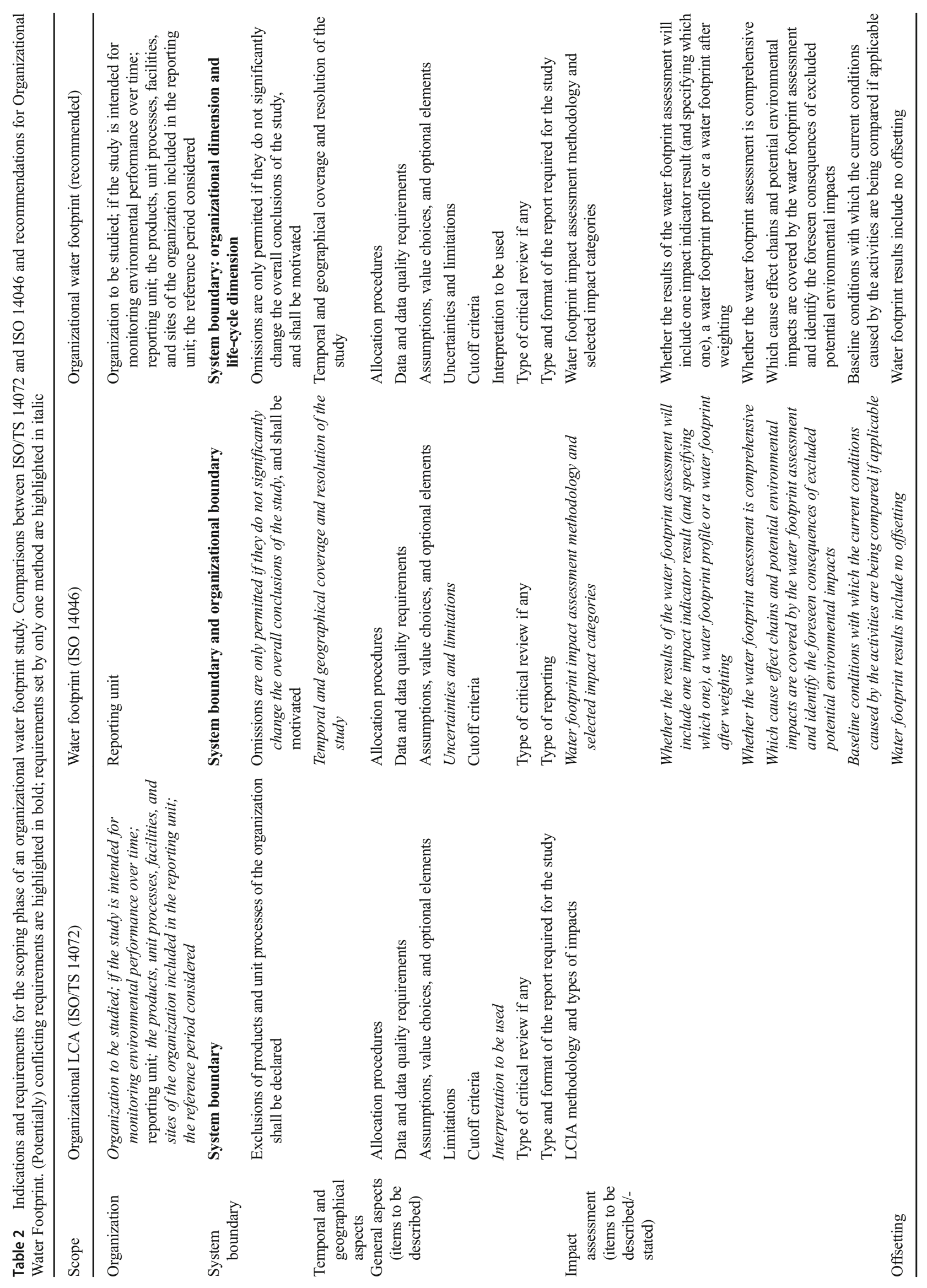




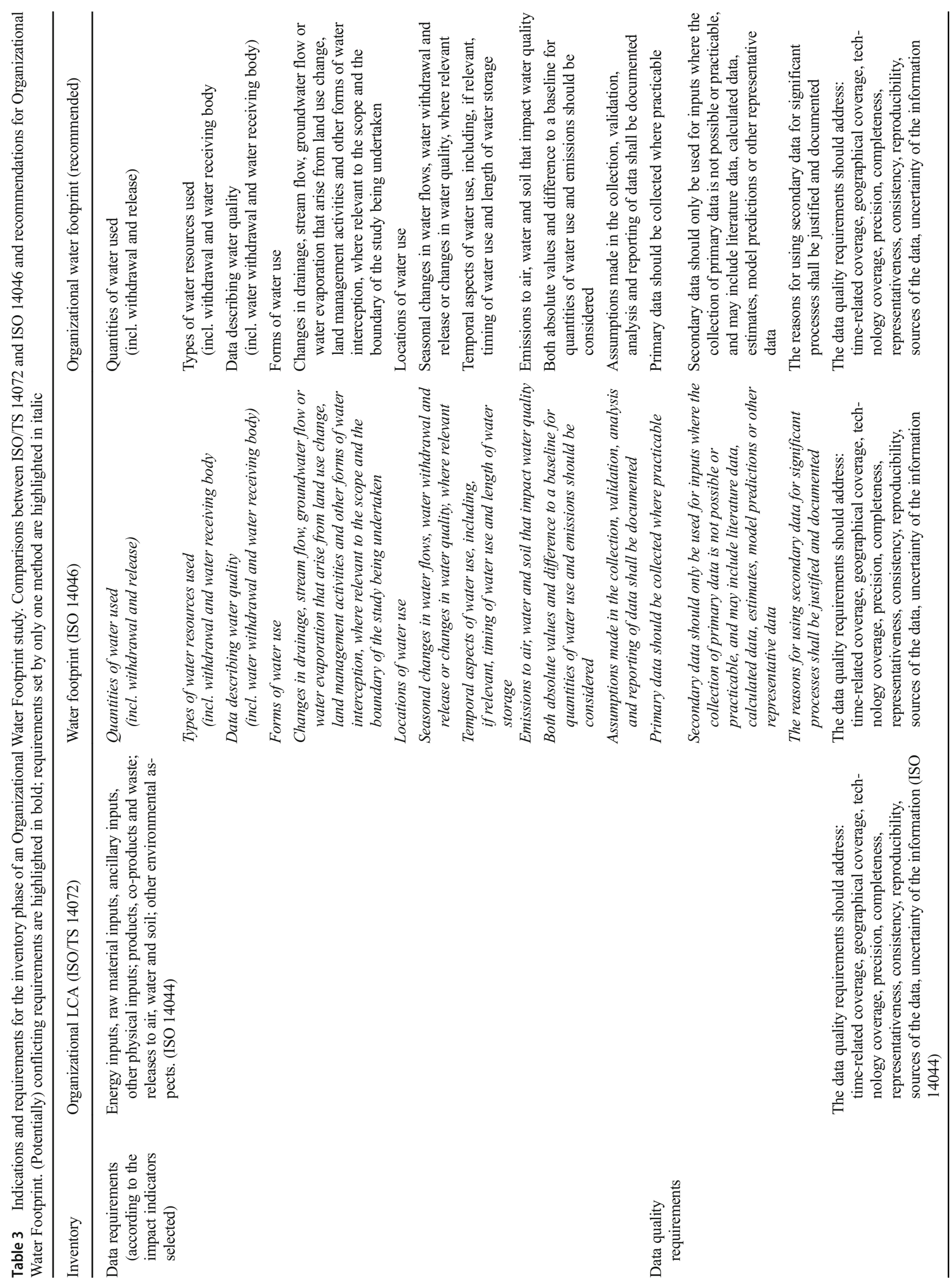


ISO/TS 14072 overlap regarding: the intended application, the reason for carrying out the study, and the intended audience. As for the product-related equivalent, also organizational water footprint assessments can be carried out either as standalone assessments or as part of an organizational life cycle assessment, and this shall be declared in the goal of the study.

The two standards contain diverging requirements on comparative assertions. On the one hand, ISO/TS 14072 requires including a statement that the results of the study are not intended to be used in comparative assertions intended to be disclosed to the public. In other words, based on the results of the organizational LCA of two organizations, it cannot be publicly stated which organization has a better environmental performance. On the other hand, ISO 14046 considers comparative assertions possible if the water footprint is conceived as part of an LCA (since no comparative assertions should be based on one or a limited set of impact indicators as delivered by a water footprint study). Transferred to the organizational level, this would mean that organizational water footprint, embedded in a multi-impact study, could be used for comparative assertions, since ISO 14046 does not highlight any exception for organizations.

A similar issue regards comparative studies, which are allowed in ISO 14046, under the premise that "the equivalence of the systems being compared shall be evaluated before interpreting the results" (ISO 14046). ISO/TS 14072 does not contain any reference to comparative studies, so that the general indications of ISO 14044 (ISO 2006a) can be assumed to be valid. $^{2}$

However, since organizations are unique according to their sector, product portfolio, size, and location of the organization itself and its suppliers (particularly relevant for the case of water), it seems arduous to establish the equivalence of two organizations. Therefore, we suggest avoiding comparisons between organizations in organizational water footprint studies. However, comparing one organization's performance across different years (performance tracking) is possible and one of the main benefits of organizational methods, besides its usefulness as analytical tool to identify possible burden shifting, as decision support for supply chain management and the prioritization of impacts reducing measures, and as information source for environmental reporting and transparent communication (see ISO/TS 14072, 5.1). If organizational methods are used for performance tracking, "structural changes to the organization should be identified, and their effects on the results of the OLCA for the relevant time period explained (e.g. merger and acquisition, BU sales, outsourcing, number of employees, etc.)" (ISO 2014b).

\footnotetext{
${ }^{2}$ ISO 14044 states that "Systems shall be compared using the same functional unit and equivalent methodological considerations, such as performance, system boundary, data quality, allocation procedures, decision rules on evaluating inputs, and outputs and impact assessment. Any differences between systems regarding these parameters shall be identified and reported."
} 


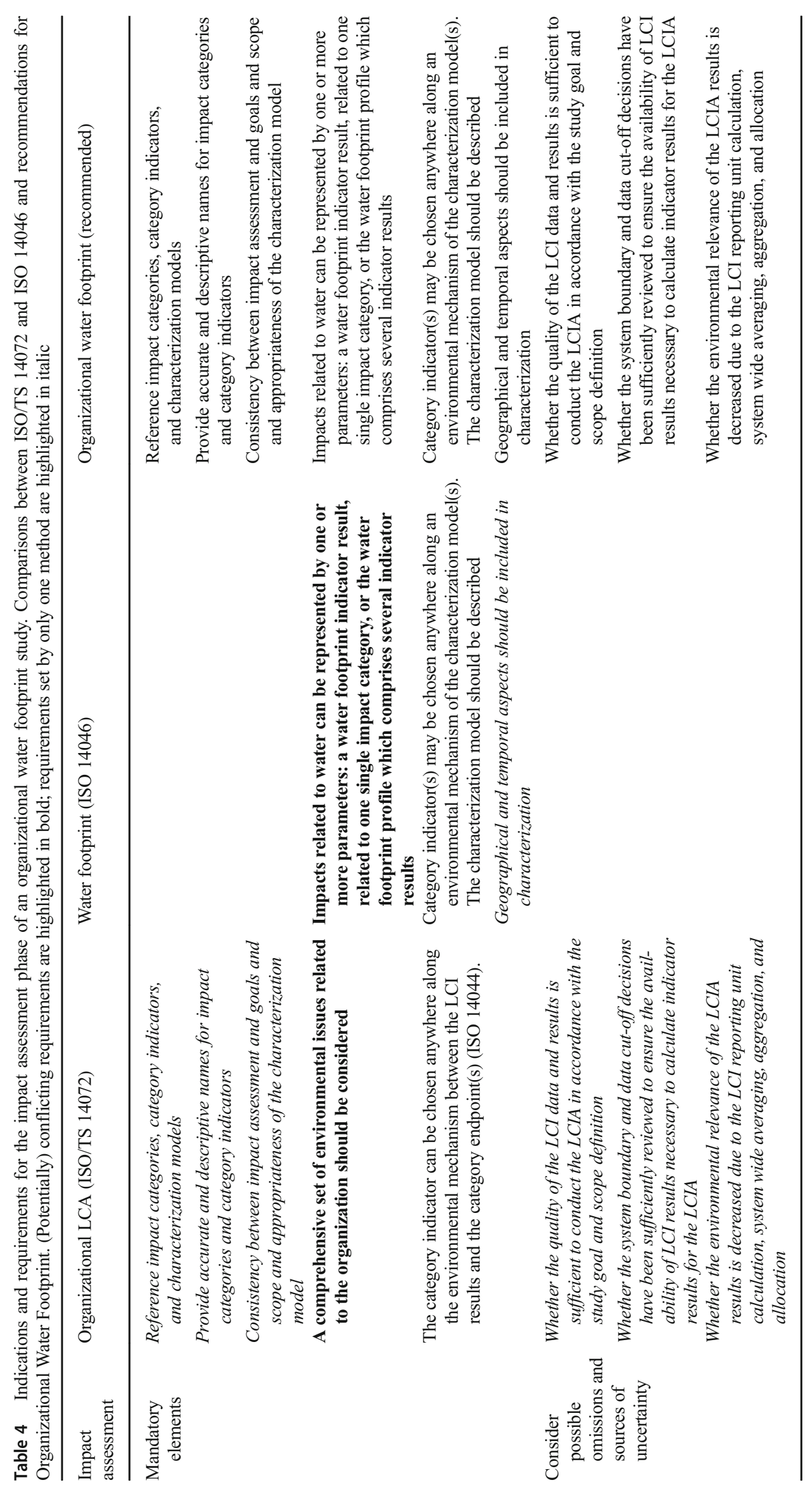




\subsubsection{Defining the scope}

The scope of the study establishes the boundaries of what is going to be analyzed and implies several methodological decisions. ISO standards provide requirements concerning the elements to be defined in the scoping phase (displayed in Table 2).

The organization-specific elements are treated in ISO/TS 14072. Following items shall be considered and clearly stated: the organization to be studied, the intention of tracking environmental performance over time, the reference period considered, the products and unit processes of the organization, and the reporting unit.

\subsubsection{Reporting unit}

According to ISO/TS 14072, the reporting unit is the quantified performance expression of the organization under study and provides a reference to which inputs and outputs can be normalized in a mathematical sense. For the case of organizations, ISO 14046 also uses the term reporting unit in substitution to the (process- and product-related) functional unit.

\subsubsection{System boundary}

The system boundary specifies the unit processes to be included in the study based on the reporting unit and the goal of the study. Both ISO/TS 14072 and ISO 14046 require to explicitly declare the boundary of the organization. However, a discrepancy can be noticed in the terminology, since ISO/TS 14072 generally refers to the system boundary, whereas ISO 14046 states that "when undertaking a water footprint assessment of an organization, the organizational boundary and the system boundary shall be determined." A glance at the organizational model depicted in Annex A (ISO 2014a) suggests that the organizational boundary refers to the facilities of the organization being studied, whereas the system boundary addresses the life cycle boundaries for products. In general, setting the system boundary proved challenging for organizational LCA (UN Environment 2017), because, under a life-cycle perspective of organizations, the boundary becomes two-dimensional.

The first dimension refers to the amount of (product) life cycles the study should consider. This means, from the perspective of organizations, which product lines, production facilities or regional units of the organization should be included. This "organizational boundary" depends on the definition of the reporting unit (or reporting organization if the O-LCA Guidance terminology is applied, see (UNEP 2015)) and is only based on the aim and scope of the study.

The second dimension represents the life cycle of the organization's products, i.e., translated into "organizational" language, the upstream and downstream activities (see (UNEP 2015)). Setting the boundary for this life-cycle-related 


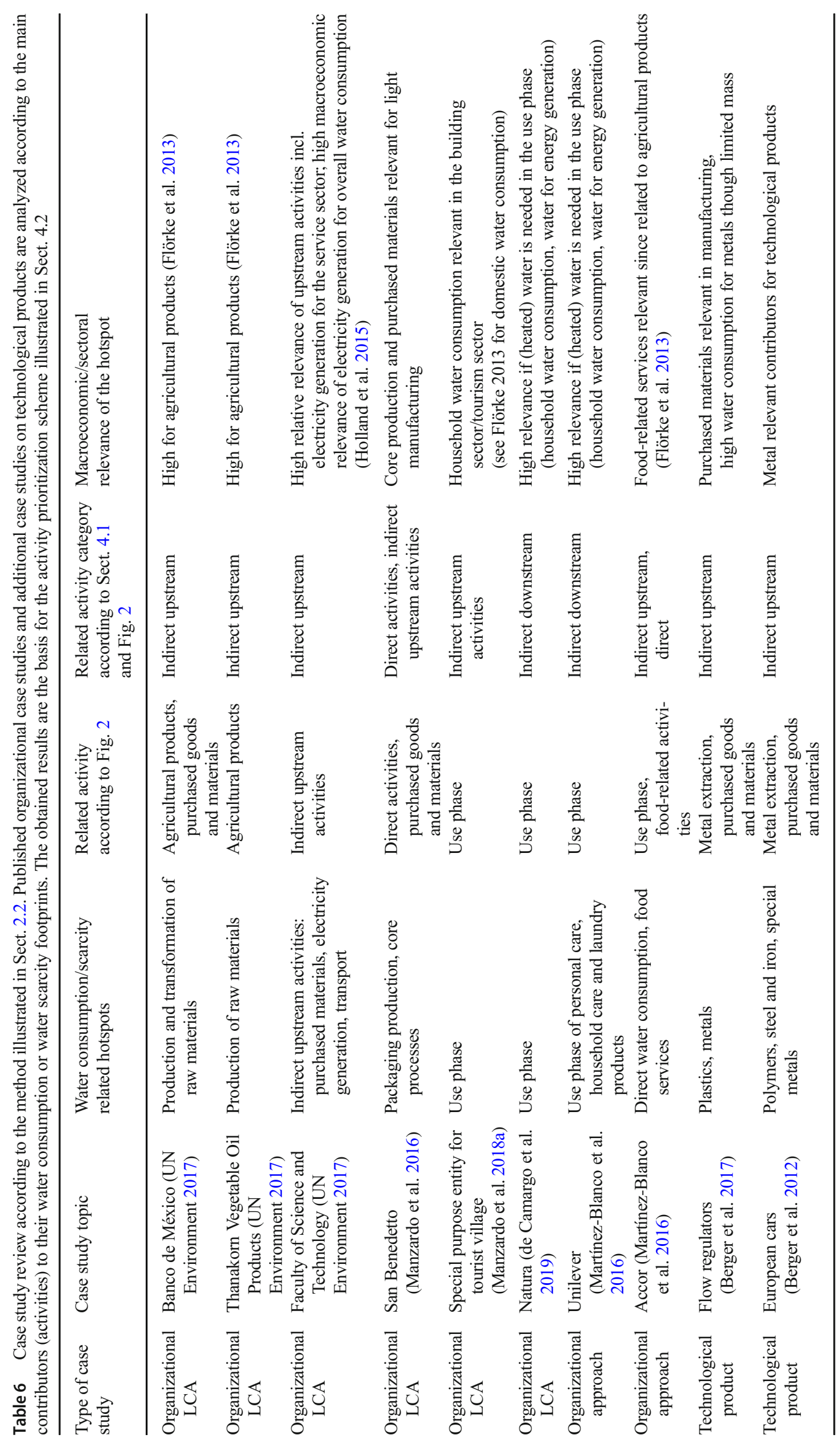


dimension means deciding how many tiers of the supply chain are included in the study. This "life-cycle" boundary needs to comply with additional requirements given by the ISO standards. In principle, all processes linked to an organization should be included in the study. However, following the unit processes related to an organization's products after these leave the organization (downstream) might be difficult if the organization acts at the beginning of the supply chain, e.g. in the raw materials sector. In such cases, and if the organization has no influence on the use stage and end-of-life stage of its products, downstream processes can be excluded (ISO 2014b). However, the use stage should be included if the organization's products are expected to have high environmental impacts during use. The water-specific recommendations from ISO 14046 should be followed in this case: "The use stage flows should be included if the products use water, consume energy, or generate emissions with potential environmental impacts on water during use like e.g. washing machines, dishwashers, apparel (requires washing and drying), food (requires cooking and refrigeration) or soaps and detergents (require heated water)." ISO 14046 does not provide specific recommendations for the inclusion of the end-of-life phase of sold products. To facilitate method application, Sect. 4.2 of this paper offers a detailed prioritization scheme for water scarcity footprints including waste management activities, which can serve as indication for the relevance of this downstream activity based on the technology used.

\subsubsection{Offsetting}

Offsetting is a calculation mechanism that allows compensating the environmental impacts of the product, process or organization under study through impact-reducing activities outside the system boundary. ISO 14046 explicitly excludes offsetting. Being related to processes that take place outside the system boundary, offsetting can be considered as implicitly excluded by all LCA-based methods, including organizational water footprint.

\subsubsection{Other aspects}

Further ISO requirements for the scoping phase regard methodological choices to be stated and applied in the inventory, impact assessment, and interpretation phase. These are included in Table 2 and explained in more detail in Sects. 3.2-3.4.

\subsection{The inventory phase}

\subsubsection{Data collection}

In the inventory phase of organizational water footprint, data for all water-relevant inputs and outputs (elementary flows) is collected and analyzed. Inventory data necessary for organizational water footprint is the same as in productrelated studies and corresponds therefore with the requirements provided in ISO 14046, more specific than the requirements for organizational LCA, which are conceived for a broader range of environmental impacts. Inventory data according to ISO 14046 includes water withdrawn from the environment and entering the system (i.e., crossing the system boundary) without previous human transformation, and water leaving the system and released to the environment without subsequent human transformation. Further inputs and outputs to be considered are substances, e.g., pollutants, which affect water quality. Their choice and collection should be performed according to the goal and scope of the study, i.e., to the impact categories addressed.

ISO 14046 provides details on the type of data to be collected for carrying out a water footprint study (Table 3 ). These requirements apply to all kinds of systems considered (product, process, or organization) and embrace data and data quality requirements. The data to be collected are as follows: the quantities of water use and data describing water quality (including withdrawal, release, and water receiving body); forms of water use (including, if relevant, changes in drainage, stream flow, groundwater flow or water evaporation); location of water use (withdrawal and release) required to determine any related environmental condition indicator of the area where the water use takes place; seasonal changes in water quantity and quality, if relevant; emissions to air, water and soil that impact water quality, and any other data needed by the water footprint impact assessment method applied.

Primary data should be preferred and the use of secondary data for relevant processes needs to be justified. Further data quality requirements should address, among others, timerelated coverage and geographical coverage, particularly relevant for water-related assessments.

Given the high amount of flows available in an organizational study, the inventory analysis might profit from aggregating inputs and outputs according to the goal of the study, as stated in ISO/TS 14072. Recommendations for inventory categorization derived from the Guidance on Organizational LCA (UNEP 2015) are described in Sect. 4.1.

\subsubsection{Temporal aspects}

Given the seasonal variability of water availability, the consideration of temporal aspects in data collection, also acknowledged more generally in ISO 14044 and therefore implicitly included in ISO/TS 14072, is particularly relevant in water-related assessments. Newly developed impact assessment methods to assess impacts of water use contain also monthly values, reflecting the seasonal character of water scarcity in several basins (Boulay et al. 2018; Berger et al. 2018). To make use of them in water scarcity footprint assessments, also inventory data needs to be collected with monthly 
resolution. This is rarely possible for data on indirect activities (see Sect. 4.1) that are often collected from secondary sources providing average values. For direct activities, monthly data might be available from internal measurements and should be preferred if an impact assessment method delivering characterization factors with monthly resolution is used. This is not in conflict with the reporting period, generally 1 year, for which organizational data is collected. In fact, the duration of the reporting period does not prevent a higher temporal granularity of inventory data, as long as data for, e.g., all months of the reporting period are available.

\subsubsection{Allocation}

When analyzing an organization's supply chain, one often faces cases of multi-functionality. For example, if a supplier delivers only one part of its goods to the reporting organization, the latter should be made accountable only for that specific part of the environmental burdens caused by the supplier's products and not for the entire suppliers' organizational water footprint (Finkbeiner and König 2013). According to both ISO 14046 and ISO/TS 14072, allocation should be avoided by dividing the processes to be allocated in subprocesses for which data is available. Another possibility to avoid allocation according to ISO 14046 is system expansion: the system boundary is widened (and the reporting flow enlarged) to include also the part of the inventory that cannot be excluded, and its whole life cycle. This system expansion option shows once more that ISO 14046 is conceived from a product perspective. In fact, in organizational studies, enlarging the system boundary would mean including further organizations in the study (other buyers of the supplier whose inventory needs to be allocated). This option would imply an enormous effort, including modeling other organizations without having access to their primary data. Therefore, the option of expanding the system boundary is excluded for organizational LCA in ISO/TS 14072. With the same argument, we propose excluding the system expansion option also for organizational water footprint. A viable option for avoiding allocation when assessing organizations is using, if known, the water-related life cycle inventory data of the purchased products (UNEP 2015). If allocation cannot be avoided, inputs and outputs should be partitioned according to physical relationships (e.g., mass, volume, etc.) or, if this is not possible, according to economic value (as indicated in both ISO 14046 and ISO/TS 14072).

In an organizational study, environmental impacts do not only need to be allocated to a certain system, but also to a certain time frame. For example, the reporting organization purchases vehicles with a life span that does not coincide with the reporting period. If the reporting period is 1 year, and a vehicle is used for 5 years, the water-related environmental impacts caused by the vehicle need to be attributed to a specific reporting period. Temporal allocation issues apply for different types of capital equipment and eventually for purchased goods, materials, services or fuels. According to ISO/TS 14072, "the calculation methodology of LCI of these assets should take into account the time period over which they are used. In that case, the calculation methodology shall be clearly justified and documented."

\subsection{Impact assessment}

In the impact assessment phase, the potential environmental impacts related to the life cycle inventory are assessed. To perform water-related impact assessment, several scientific impact assessment methods are available (Kounina et al. 2013). ISO standards do not provide specific guidance on which impact assessment methods should be preferred, but set requirements impact assessment methods should fulfill (like the environmental relevance of category indicators and characterization models) and state the mandatory character of classification and characterization.

ISO/TS 14072 adapts life cycle impact assessment to the organizational level by highlighting possible omissions or sources of uncertainty that need to be accounted for inventory data quality, consideration of system boundary and cutoff decisions, influence of reporting unit calculation, system-wide averaging, aggregation and allocation of the LCIA results.

ISO 14046 deals with impact assessment in a more waterspecific way. It requires reflecting the impact indicators chosen in the definition of the study (water scarcity footprint, water degradation footprint) if only a limited set of waterrelated indicators are chosen, while the term water footprint shall only be used for a comprehensive water footprint assessment. The choice of category indicators is free, and category indicators may be chosen along the environmental mechanism described in the characterization model. ISO 14046 requires considering the geographical and temporal dimension and suggests distinguishing environmental issues pertaining different types of water resources. Further aspects are included in Table 4.

\subsection{Interpretation}

Interpreting the results delivered by a life-cycle oriented study includes identifying significant potential environmental impacts caused by the system under study, based on LCI and LCIA results; evaluating completeness, sensitivity and consistency; identifying limitations of the study; conclusions and recommendations (ISO 2014a). ISO/TS 14072 requires that, for organizations, modifications to the reporting unit, reference period, and system boundary are considered. This is of particular relevance for performance tracking. In fact, if the organization's performance of two different time periods is compared, changes in the organization's structure (outsourced 
activities, mergers, etc.) and in the product portfolio need to be accounted for in order to track the sources of change in overall environmental impacts. Moreover, it should be discussed whether the reporting unit and the system boundary are in line with the goal of the study.

Additionally, ISO 14046 explicitly requires identifying the processes that significantly contributed to the water footprint results, the environmental mechanisms mainly affected, and the elementary flows that mainly contribute to the results of the water footprint assessment. Further, geographical and temporal aspects shall be included in the interpretation. Further aspects are included in Table 5.

\section{Application of organizational water footprint}

Among the main challenges of organizational activities, data collection has been identified as a particularly demanding task (UN Environment 2017). In the following, method application guidance to facilitate data categorization according to the $\mathrm{O}$ LCA Guidance (UNEP 2015) is delivered (Sect. 4.1) and an activity prioritization scheme for the specific case of water scarcity footprints (single-indicator assessment) is proposed (Sect. 4.2).

\subsection{Categorizing activities}

One of the main challenges of conducting an organizational study is understanding which inventory data should be considered and categorizing it in a consistent way (UN Environment 2017). To cope with it, organizational methods such as organizational LCA (UNEP 2015) and the GHG Protocol (WBCSD/WRI 2004) recommend to categorize inventory data according to their location in the organization's supply chain. The categorization of inventory data into activities helps modeling the organization and understanding the data needs related to different parts of the supply chain. The O-LCA Guidance offers a framework to categorize activities into direct, indirect upstream and indirect downstream activities.

1. Direct activities are owned or controlled by the organization under study and include, for a producing company, all the elementary flows linked to the organization's facilities, e.g., the inputs and outputs linked to physical or chemical processing, water consumption, on-site energy generation, transport activities with vehicles owned by the company, waste treatment in company-owned facilities.

Indirect activities (not part of the reporting organization) are classified as:

2. Indirect upstream activities, if they are carried out by upstream suppliers or support the organization (e.g., purchased raw materials and intermediate products, outsourced services such as cleaning, marketing or IT, external waste treatment, capital equipment such as machinery and buildings, transport of materials to the organization);

3. Indirect downstream activities, if they take place after the products leave the organization (e.g., transport of products from the organization to the costumer, logistics, use phase, end-of-life phase).

An overview of activities possibly carried out by an organization and relevant for an organizational water footprint study is delivered in Fig. 2. It should be noticed that defining and classifying an organization's activities is not required by ISO standards. In fact, ISO/TS 14072 does not refer to activities and requires collecting data for unit processes and relating them to the reporting unit. In this respect, activities can be seen as collections of unit processes with a twofold purpose. First, indicating "where to look at" when beginning collecting data for an organization: activities can therefore be used as a checklist for practitioners "not to oversee" possibly relevant elementary flows. Second, activities help, in a first screening, identifying hotspots to be analyzed in depth by disaggregating them into the unit processes they entail. From this perspective, they constitute the "level of aggregation [...] consistent with the goal and scope of the study" at which inputs and outputs should be analyzed according to ISO 14046 and ISO/TS 14072.

\subsection{Prioritizing data collection: specific guidance for organizational water scarcity footprint}

Due to the time intensity of data collection, it is necessary to prioritize data collection efforts based on the capacities available for the case study. Valuable general criteria (quantitative and organizational aspects) are provided by the O-LCA Guidance (UNEP 2015). However, the multi-impact nature of O-LCA prevents a prioritization according to the activity type, since several impact categories are considered that might be relevant for different activities. For the case of water scarcity footprint, where less indicators are potentially concerned, specific guidance on activities prioritization can be delivered based on available case studies. Table 6 summarizes, for the available organizational LCA case studies including water consumption or water scarcity among their inventory or impact assessment results, the main contributing activities. Based on this empirical knowledge base, we define criteria for prioritizing data collection for the specific case of a water scarcity footprint study, for widespread activities in companies belonging to the producing industry. We divide activities into three categories: high priority (red boxes in Fig. 2), average 


\section{Outputs}

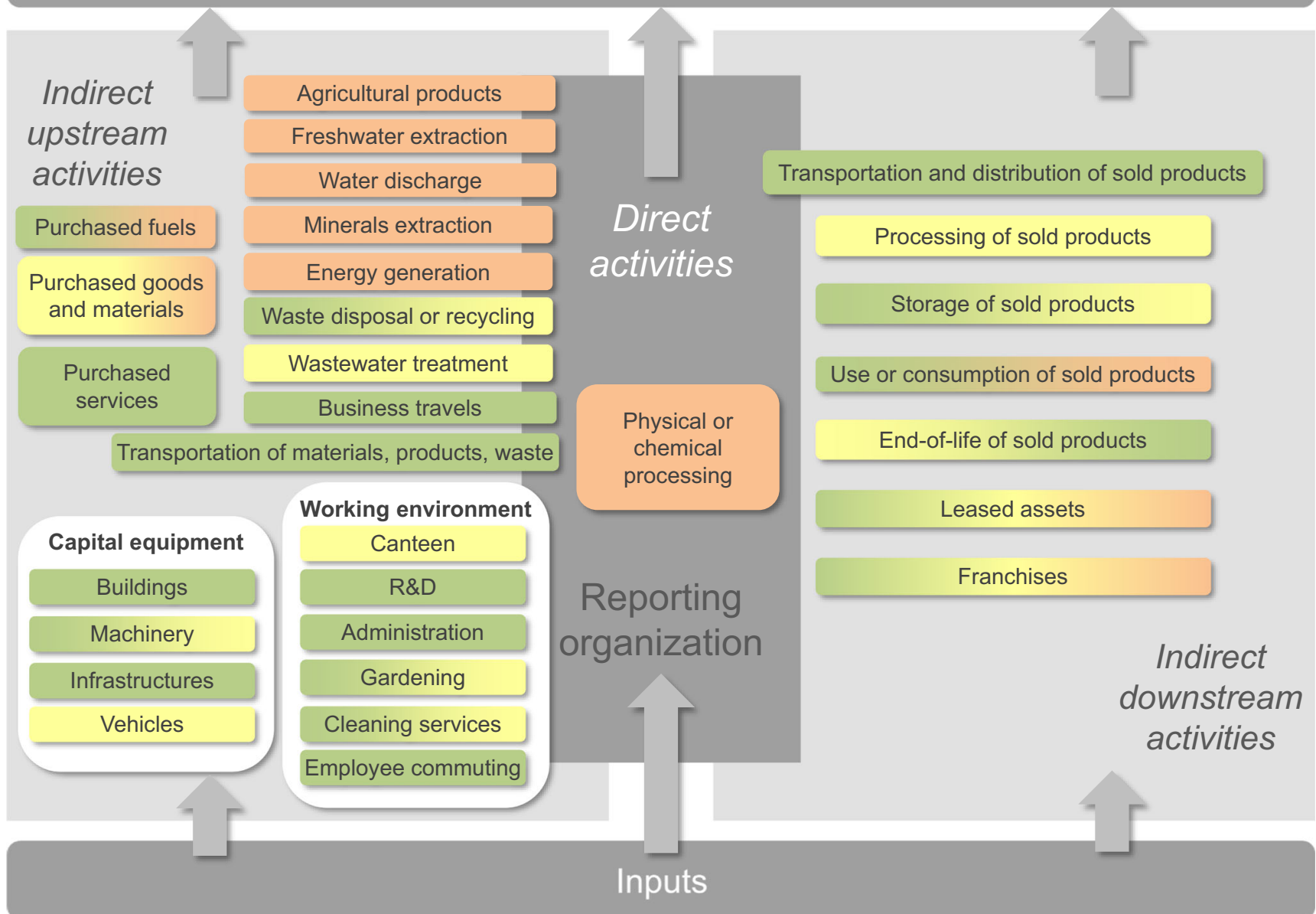

Fig. 2 Direct and indirect activities carried out by an organization (example for the producing industry), and guidelines for prioritizing data collection for a water scarcity footprint study (red: high priority;

priority (yellow in Fig. 2) and low priority (green in Fig. 2). This prioritization scheme is motivated in the following, with explanations on the high priority activities and the activities highlighted as variable priority (more than one color in Fig. 2). Since the range of available case studies is limited, additional literature is taken into account: two published case studies following an organizational approach that can be considered as predecessors of organizational LCA (Martínez-Blanco et al. 2016; UNEP 2015), and case studies on technological products (Berger et al. 2012, 2017). For activities classified as variable priority activities, comparative case studies (e.g., on fuels types or waste management options) are used to highlight the technology dependence of an activity's water scarcity footprint.

\subsubsection{High-priority activities}

Direct activities are attributed high priority because of their direct ties to the organization and the strong influence the yellow: average priority; green: low priority). Adapted from UNEP (2015)

organization has on possible impact reduction measures, although the actual environmental relevance depends on the kind of processes carried out within the organization and the organization's location. Among the case studies illustrated in Table 6, for example, only the San Benedetto facility in Scorzè analyzed by Manzardo et al. (2016) shows a relevant contribution of direct activities to water depletion.

For indirect activities, we prioritize according to their environmental relevance based on organizational case studies available. With this regard, practitioners should bear in mind that the environmental relevance of individual activities resulting from the impact assessment depends on the impact assessment method used. If for example a withdrawal-based method is used, e.g. WSI (Pfister et al. 2009), activities causing consistent water withdrawal should be prioritized; if a consumption-based method is chosen, e.g., Aware or WAVE(+) (Boulay et al. 2018; Berger et al. 2014, 2018), the focus should be set on activities associated with high water consumption. The indirect activities expected to have 
the highest impact on water scarcity are as follows: freshwater extraction and discharge, agricultural products, minerals extraction, and energy generation. In Fig. 2, these activities are displayed between the direct and the indirect upstream category. In fact, though generally not belonging to the reporting organization, these activities might be (partly) owned by the reporting organization (e.g., if the organization produces part of the consumed electricity through own photovoltaic plants or extracts freshwater directly from the environment).

It should be noticed that, if freshwater is not extracted by the organization, the amount of water used to produce the water delivered to the organization represents indirect water consumption. The organization's direct water consumption is the amount of (treated) water entering the organizational boundary, minus the amount of discharged water. Besides freshwater extraction, also water discharge should be highly prioritized, since knowing the quantity of discharged water allows calculating water consumption.

Agricultural activities are responsible for $70 \%$ of worldwide water withdrawals, followed by the industrial sector (19\%) and households (11\%) (Flörke et al. 2013). Organizational case studies in which the agricultural sector was involved in the supply chain also show a high contribution of the agricultural supply chain to overall water consumption/scarcity (see, e.g., Banco de México and Thanakorn in (UN Environment 2017)). However, the water consumption values of different agricultural products strongly diverge, as shown in a comparison by Hoekstra and Mekonnen for crops and dairy products (Mekonnen and Hoekstra 2012a; Stoessel et al. 2012). Specific attention should be devoted to agricultural products requiring high amounts of freshwater that are usually grown in water-scarce regions and/or seasons (Chapagain and Orr 2009; Chu et al. 2017).

Energy generation is responsible for a relevant share of global industrial and domestic water consumption (Holland et al. 2015). The main driver for water use in energy production is electricity generation (Zhang and Anadon 2013; Holland et al. 2015), though with high variance depending on the fuel type and generation system employed. The least water-consuming energy generation systems are non-thermal renewables such as photovoltaics and wind. Concentrating solar power, nuclear power, and coal (recirculating cooling) cause consistently higher water consumption per unit of energy produced (Macknick et al. 2012), while the highest water consumption is attributed to hydropower (Mekonnen and Hoekstra 2012b). Before this backdrop, the upstream activity energy generation should be accorded high priority. If known, the generation technology employed should be taken into account for the study as well as in the interpretation phase. Knowledge about the energy sources and production technology in place might be useful also to provide recommendations or put in place measures to reduce the organization's water footprint.

Minerals extraction is subject to high water consumption per unit of mineral extracted, with gold, platinum, diamonds, uranium, and copper belonging to the most water-consuming minerals in the extraction phase (Mudd 2008). Considering the life cycle of metals production (cradle-to-gate), it can be noticed that the global production of each commodity impacts local water stress to a different extent, depending on the quantities of mineral extracted and processed and the location of water consumption. The highest effects on water scarcity were found to be caused by chromium, copper (leaching), molybdenum, platinum, and silver (Northey et al. 2014). In general, both the technology used at the extraction stage and the geographical location of the mine are relevant for the water footprint determined by mineral extraction. Therefore, data for this upstream activity need to be collected carefully, and primary data are preferable.

\subsubsection{Activities with variable priority}

Certain upstream activities need to be (highly) prioritized, i.e., are expected to have a high water withdrawal or consumption only under certain circumstances. These are purchased fuels, purchased goods and materials, and (organizational) waste disposal and recycling. Since no disaggregated results are available for these activities in organizational case studies including water scarcity related impact assessment, comparative case studies at the product or commodity scale are used to support prioritization.

When considering purchased fuels, particular attention should be payed if biofuels are involved. According to comparative studies by Berger et al. (2015) and Pfister and Scherer (2015), biodiesel and bioethanol have the highest water footprint (three orders of magnitude higher than petrol and diesel). However, one should distinguish between first-generation and second-generation biofuels, the latter expected to have a lower water footprint because they are primarily based on waste (Chiu et al. 2015).

Providing guidance for prioritizing data collection for purchased goods and services is very difficult due to the diverse range of materials possibly involved. In general, services can be assumed to have a relatively low water footprint. For purchased goods and materials, it should be considered whether they include, in their life cycle, any of the high-priority activities mentioned above (agricultural goods, minerals, high energy consumption). In this case, data collection needs to be prioritized. If primary data from suppliers are not available, secondary data can be used for modeling purchased goods.

Also the treatment of the organization's waste should be prioritized according to the waste treatment technology used. As Fernández-Nava et al. (2014) show, municipal solid waste options cause different amounts of water consumption, with 


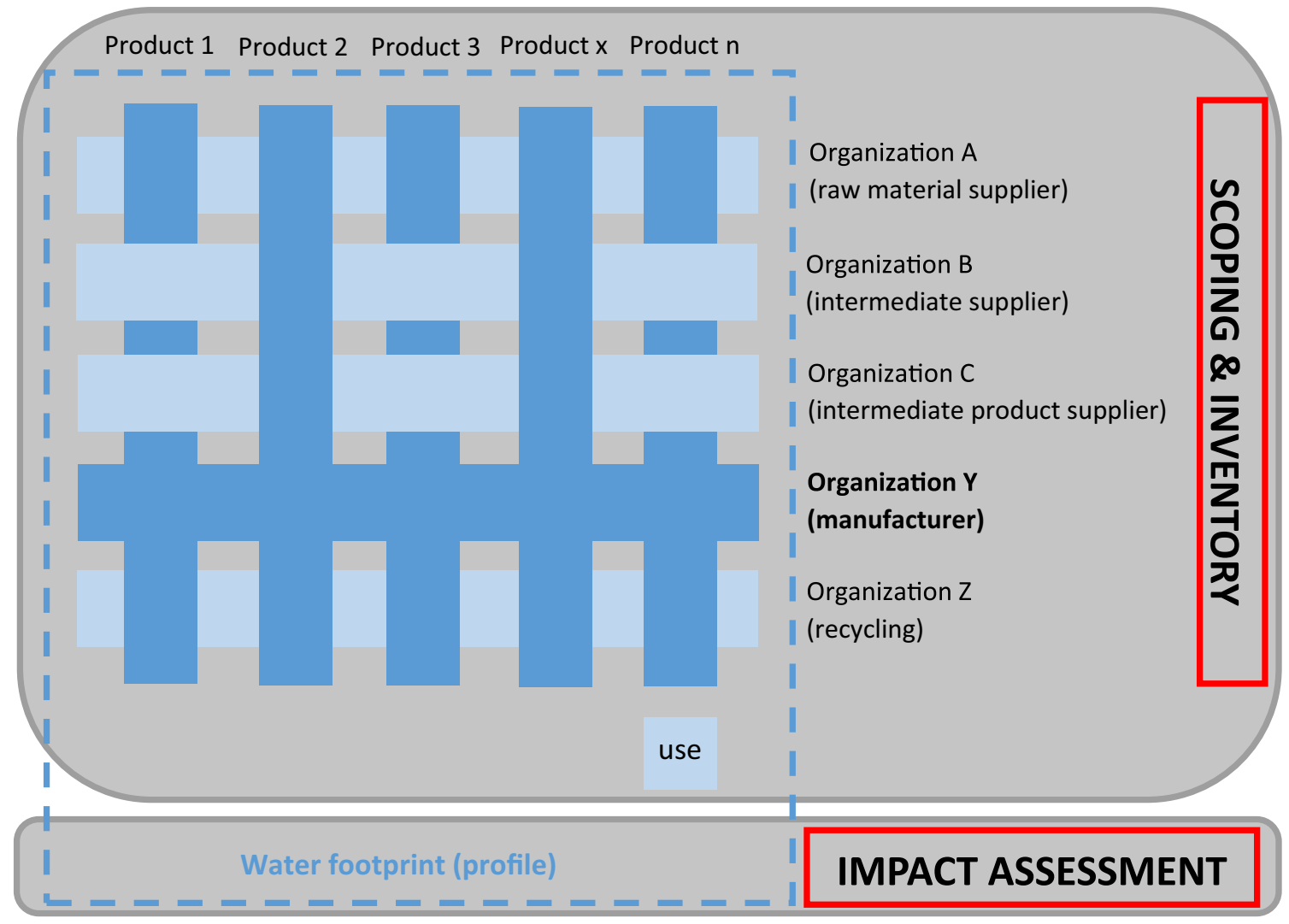

Fig. 3 Methodological structure for organizational water footprint. Adapted from Finkbeiner et al. (1998)

biomethanization and landfill of non-stabilized waste consuming the largest amounts of water (899 and $762 \mathrm{~kg}$ water/t waste, respectively). Comparable results are obtained by Herva et al. (2014) and Hong et al. (2017).

Among the supporting activities, also machinery, gardening and cleaning services have varying priority levels. Machinery is usually made of metals. Therefore, if machines containing a large amount of metals are used for production, data on the material composition and mass should be collected. Water consumption for gardening activities should be prioritized depending on the surface of the garden belonging to the organization and its location. The water consumption for cleaning services depends on the type of cleaning required by the processes carried out within the organization.

As for upstream activities, also certain downstream activities have a variable prioritization level. For leased assets and franchises, the priority level depends on the type of goods or services leased or franchised. Practitioners can act according to the corresponding activities, if outlined elsewhere. For example, if vehicles are leased, the prioritization level for the upstream activity vehicles (capital equipment) should be followed.

The use or consumption of sold products should be prioritized according to the water and energy needed by the product during the use phase. The use phase proved crucial in available organizational studies for building-related activities (Manzardo et al. 2018a; Martínez-Blanco et al. 2016) and for body care and cleaning products (de Camargo et al. 2019; Martínez-Blanco et al. 2016). The prioritization of the end-of-life stage depends on the type of waste treatment foreseen in the country or countries where the product is disposed. The same considerations as for the organization's waste apply. Finally, data collection for products' storage should be accorded average priority if electricity for cooling is required.

\section{Discussion}

Juxtaposing ISO/TS 14072 and ISO 14046 allowed establishing a consistent set of requirements to carry out an organizational water footprint study. The different foci of the two methods explain the differences between the two standards and allow for a comprehensive set of indications. As a result, a water footprint method for organizations could be outlined, which profits from both the strengths of organizational LCA in modeling an organization's supply chain and those of water footprint in guiding through water-specific issues in the inventory and impact assessment phase (see Fig. 3).

Unclear or conflicting requirements could be identified:

i) For the case of comparisons, it becomes evident that ISO 14046 is conceived for product-related studies, prone to comparisons with reference to the functional 
unit. Differently than for products, the functions of different organizations cannot be unequivocally quantified, so that even the quantification of the product portfolio is subject to the conceptual choices linked to the reporting flow. For this reason, ISO/TS 14072 de facto does not support comparisons between different organizations. Juxtaposing the two methods highlighted this inconsistency, amended in this paper by the suggestion to avoid comparisons at all in organizational studies intended for publications. Differently, comparisons among different production lines of the same organization are allowed, since the overall organization's characteristics remain equal and no competition issues are affected. Also, the comparison of the same organization's performance in different years (performance tracking) is possible within an organizational framework and is explicitly addressed in ISO/TS 14072.

ii) Further ambiguous requirements are linked to the system boundary. When considering organizations, both the parts of the organization assessed in the study and the part of the supply chain considered (cradle-to-gate or cradle-to-grave) need to be stated. To avoid confusion, we suggest acknowledging the twodimensionality of organizational system boundaries as in ISO 14046 by explicitly defining a life-cycle dimension and an organizational dimension of the system boundary. We suggest naming these dimensions "organizational boundary" and "life cycle boundary," and using the term "system boundary" as overarching concept to describe both. While setting the system boundary, practitioners should be aware that these dimensions might overlap. For example, if the organization owns or controls both the production and the distribution of goods, two life-cycle stages will be covered within the organizational boundary, i.e., the production phase and the distribution phase, the latter otherwise accounted as downstream when following the supply-chain logic, or possibly erroneously double-counted. To sum up, a semantic differentiation would let practitioners analyzing the organization's structure and the life-cycle dimension consciously within the same methodological step, which might help avoiding double-counting, e.g., if one facility is part of the organization and supplier of another organizational facility or owned/controlled activity at the same time.

iii) System expansion as an option to avoid allocation is considered in the product-focused ISO 14046, but excluded in ISO/TS 14072 because expanding the inventory in an organizational study considerably complicates access to and collection of the necessary data. Given the organizational scope of organizational water footprint, we recommend following ISO/TS 14072 on this issue.
This paper also demonstrates that the complexity of an organizational study can be a priori reduced for single-indicator assessments by prioritizing data collection. The exercise has been conducted for organizational water scarcity assessment via literature research. A similar approach might be applied to other singleindicator assessment frameworks targeting organizations.

Additionally, the suitability of product-related impact assessment methods used for product water footprint should be considered carefully. Annex A to ISO 14046 does not mention impact assessment-related issues, which suggests that no changes to requirements for product-related studies are necessary for performing assessments at the organizational level.

However, adaptation might be needed for assessing water scarcity. So far, most water scarcity assessment methods have been originally developed for marginal changes, i.e., assuming that the system under study does not change the background water availability in the basin affected. This is the case for most product systems, being the functional unis assumed as "sufficiently small." However, it cannot be excluded that a large organization causing a high water consumption in a specific basin changes the overall water availability in that basin to such an extent that local water scarcity might be affected (Boulay et al. 2017). For this reason, while carrying out a water scarcity footprint study, practitioners should carefully consider which share of local water consumption the organization is responsible for-and consider non-marginal approaches (e.g., average as in Pfister and Bayer (2014) or "dynamic" as conceptualized in Boulay et al. 2017)) for performing impact assessment.

\section{Conclusions and outlook}

This paper addresses the methodological elements and requirements for carrying out an organizational water footprint study. For the four phases of LCA (goal and scope definition, inventory analysis, life cycle impact assessment, and interpretation) the requirements provided for organizational LCA (ISO/TS 14072) and water footprint (ISO 14046) were hybridized. In line with the respective focus, ISO/TS 14072 provides guidance for organization-related elements, particularly relevant for the scoping phase, since the study design needs to fit the particular nature of the system. Before this backdrop, we suggest taking ISO/TS 14072 as a normative reference for the scoping phase of organizational assessments. Indications from ISO 14046 prove particularly useful for the inventory and impact assessment phase, due to the focus on water-related issues. The conflicting elements identified (comparisons, system boundary, allocation) could be solved and guidance is provided. In addition, literature-based prioritization criteria 
to facilitate data collection, especially for water scarcity footprint assessments, are delivered. This should lead to a more straightforward applicability of organizational water footprint and foster method application.

Given the broad definition of organizations, practitioners dealing with large water inventories might reach the limits of the marginal impact assessment methods currently used e.g. for water scarcity assessments, if the water consumed by the organization strongly affects the background water availability in a certain basin. This drawback of widely spread impact assessment approaches should be further addressed in future research.

Acknowledgments This paper was developed in the context of the research project "Wasserfußabdruck für Unternehmen - Locale Maßnahmen in globalen Wertschöpfungsketten (WELLE)," founded by the German Federal Ministry of Education and Research (BMBF), funding measure "Water as a global resource (GRoW)," grant number 02WGR1429A. The authors would like to thank the Federal Ministry of Education and Research for the financial support and the WELLE project partners for their valuable feedback.

Open Access This article is distributed under the terms of the Creative Commons Attribution 4.0 International License (http:// creativecommons.org/licenses/by/4.0/), which permits unrestricted use, distribution, and reproduction in any medium, provided you give appropriate credit to the original author(s) and the source, provide a link to the Creative Commons license, and indicate if changes were made.

\section{References}

Berger M, Warsen J, Krinke S, Bach V, Finkbeiner M (2012) Water footprint of European cars. Potential impacts of water consumption along automobile life cycles. Environ Sci Technol 46(7):40914099. https://doi.org/10.1021/es2040043

Berger M, van der Ent R, Eisner S, Bach V, Finkbeiner M (2014) Water accounting and vulnerability evaluation (WAVE). Considering atmospheric evaporation recycling and the risk of freshwater depletion in water footprinting. Environ Sci Technol 48(8):4521-4528. https://doi.org/10.1021/es404994t

Berger M, Pfister S, Bach V, Finkbeiner M (2015) Saving the Planet's climate or water resources? The trade-off between carbon and water footprints of European biofuels. Sustainability 7(6):6665-6683. https://doi.org/10.3390/su7066665

Berger M, Söchtig M, Weis C, Finkbeiner M (2017) Amount of water needed to save $1 \mathrm{~m} 3$ of water. Life cycle assessment of a flow regulator. Appl Water Sci 7(3):1399-1407. https://doi.org/10.1007/ s13201-015-0328-5

Berger M, Eisner S, van der Ent RJ, Floerke M, Link A, Poligkeit J, Bach V, Finkbeiner M (2018) Enhancing the water accounting and vulnerability evaluation model. WAVE Environ Sci Technol 52:1075710766. https://doi.org/10.1021/acs.est.7b05164

Boulay A-M, Benini L, Bjørn A, Sala S (2017 Brussels, Belgium) Marginal or non-marginal contribution to water scarcity footprint: different approaches

Boulay A-M, Bare J, Benini L, Berger M, Lathuillière MJ, Manzardo A, Margni M, Motoshita M, Núñez M, Pastor AV, Ridoutt B, Oki T, Worbe S, Pfister S (2018) The WULCA consensus characterization model for water scarcity footprints. Assessing impacts of water consumption based on available water remaining (AWARE). Int J Life
Cycle Assess 23(2):368-378. https://doi.org/10.1007/s11367-017$1333-8$

Buxmann K, Koehler A, Thylmann D (2016) Water scarcity footprint of primary aluminium. Int J Life Cycle Assess 21(11):1605-1615. https://doi.org/10.1007/s11367-015-0997-1

Chapagain AK, Orr S (2009) An improved water footprint methodology linking global consumption to local water resources. A case of Spanish tomatoes. J Environ Manag 90(2):1219-1228. https://doi. org/10.1016/j.jenvman.2008.06.006

Chiu CC, Shiang W-J, Lin CJ, Wang C-H, Chang D-M (2015) Water footprint analysis of second-generation bioethanol in Taiwan. $\mathrm{J}$ Clean Prod 101:271-277. https://doi.org/10.1016/j.jclepro.2015. 03.068

Chu Y, Shen Y, Yuan Z (2017) Water footprint of crop production for different crop structures in the Hebei southern plain, North China. Hydrol Earth Syst Sci 21(6):3061-3069. https://doi.org/10.5194/ hess-21-3061-2017

de Camargo AM, Forin S, Macedo K, Finkbeiner M, Martínez-Blanco J (2019) The implementation of organizational LCA to internally manage the environmental impacts of a broad product portfolio. An example for a cosmetics, fragrances, and toiletry provider. Int $\mathrm{J}$ Life Cycle Assess 24(1):104-116. https://doi.org/10.1007/s11367018-1502-4

European Commission (2012) Organizational Environmental Footprint (OEF) Guide

Fang K, Heijungs R, de Snoo GR (2014) Theoretical exploration for the combination of the ecological, energy, carbon, and water footprints. Overview of a footprint family. Ecol Indic 36:508-518. https://doi. org/10.1016/j.ecolind.2013.08.017

Fernández-Nava Y, del Río J, Rodríguez-Iglesias J, Castrillón L, Marañón E (2014) Life cycle assessment of different municipal solid waste management options. A case study of Asturias (Spain). J Clean Prod 81:178-189. https://doi.org/10.1016/j. jclepro.2014.06.008

Finkbeiner M (2009) Carbon footprinting - opportunities and threats. Int J Life Cycle Assess 14(2):91-94. https://doi.org/10.1007/s11367009-0064-X

Finkbeiner M, König P (2013) Carbon footprint and life cycle assessment of organizations. JEAM 1(1):55-63. https://doi.org/10.5890/JEAM. 2012.01.005

Finkbeiner M, Wiedemann M, Saur K (1998) A comprehensive approach towards product and organisation related environmental management tools. Int J Life Cycle Assess 3(3):169-178. https://doi.org/ 10.1007/BF02978825

Flörke M, Kynast E, Bärlund I, Eisner S, Wimmer F, Alcamo J (2013) Domestic and industrial water uses of the past 60 years as a mirror of socio-economic development. A global simulation study. Glob Environ Chang 23(1):144-156. https://doi.org/10.1016/j. gloenvcha.2012.10.018

Forin S, Berger M, Finkbeiner M (2018) Measuring water-related environmental impacts of organizations. Existing methods and research gaps. Adv Sustain Syst 94:1700157. https://doi.org/10.1002/adsu. 201700157

Hertwich EG, Peters GP (2009) Carbon footprint of nations. A global, trade-linked analysis. Environ Sci Technol 43(16):6414-6420. https://doi.org/10.1021/es803496a

Herva M, Neto B, Roca E (2014) Environmental assessment of the integrated municipal solid waste management system in Porto (Portugal). J Clean Prod 70:183-193. https://doi.org/10.1016/j. jclepro.2014.02.007

Hoekstra AY (2011) The water footprint assessment manual. Setting the global standard, 1. Publ. Earthscan, London

Holland RA, Scott KA, Flörke M, Brown G, Ewers RM, Farmer E, Kapos V, Muggeridge A, Scharlemann JPW, Taylor G, Barrett J, Eigenbrod F (2015) Global impacts of energy demand on the freshwater resources of nations. Proc Natl Acad Sci U S A 
112(48):E6707-E6716. https://doi.org/10.1073/pnas. 1507701112

Hong J, Han X, Chen Y, Wang M, Ye L, Qi C, Li X (2017) Life cycle environmental assessment of industrial hazardous waste incineration and landfilling in China. Int J Life Cycle Assess 22(7):1054-1064. https://doi.org/10.1007/s11367-016-1228-0

ISO (2006a) ISO 14044: Environmental management - Life cycle assessment - Requirements and guidelines

ISO (2006b) ISO 14064: Greenhouse gases - Part 1: Specification with guidance at the organization level for quantification and reporting of greenhouse gas emissions and removals

ISO (2009) ISO 14040: Environmental management - Life cycle assessment - Principles and framework

ISO (2013a) ISO/TS 14067: Greenhouse gases - Carbon footprint of products - Requirements and guidelines for quantification and communication

ISO (2013b) ISO/TS 14069: Greenhouse gases - Quantification and reporting of greenhouse gas emissions for organizations Guidance for the application of ISO 14064-1

ISO (2014a) ISO 14046: Environmental management - Water footprint Principles, requirements and guidelines

ISO (2014b) ISO/TS 14072: Environmental management - Life cycle assessment - Requirements and guidelines for organizational life cycle assessment

Jungbluth N, Keller R, König A (2016) ONE TWO WE-life cycle management in canteens together with suppliers, customers and guests. Int J Life Cycle Assess 21(5):646-653. https://doi.org/10. 1007/s11367-015-0982-8

Kounina A, Margni M, Bayart J-B, Boulay A-M, Berger M, Bulle C, Frischknecht R, Koehler A, Milà i Canals L, Motoshita M, Núñez M, Peters G, Pfister S, Ridoutt B, van Zelm R, Verones F, Humbert S (2013) Review of methods addressing freshwater use in life cycle inventory and impact assessment. Int J Life Cycle Assess 18(3): 707-721. https://doi.org/10.1007/s11367-012-0519-3

Lo-Iacono-Ferreira VG, Torregrosa-López JI, Capuz-Rizo SF (2016) Use of life cycle assessment methodology in the analysis of ecological footprint assessment results to evaluate the environmental performance of universities. J Clean Prod 133:43-53. https://doi.org/10. 1016/j.jclepro.2016.05.046

Loiseau E, Roux P, Junqua G, Maurel P, Bellon-Maurel V (2013) Adapting the LCA framework to environmental assessment in land planning. Int J Life Cycle Assess 18(8):1533-1548. https://doi.org/ 10.1007/s11367-013-0588-y

Loiseau E, Roux P, Junqua G, Maurel P, Bellon-Maurel V (2014) Implementation of an adapted LCA framework to environmental assessment of a territory. Important learning points from a French Mediterranean case study. J Clean Prod 80:17-29. https://doi.org/ 10.1016/j.jclepro.2014.05.059

Loiseau E, Aissani L, Le Féon S, Laurent F, Cerceau J, Sala S, Roux P (2018) Territorial life cycle assessment (LCA). What exactly is it about? A proposal towards using a common terminology and a research agenda. J Clean Prod 176:474-485. https://doi.org/10. 1016/j.jclepro.2017.12.169

Macknick J, Newmark R, Heath G, Hallett KC (2012) Operational water consumption and withdrawal factors for electricity generating technologies. A review of existing literature. Environ Res Lett 7(4): 45802. https://doi.org/10.1088/1748-9326/7/4/045802

Manzardo A, Loss A, Mazzi A, Scipioni A (2016) Organization life-cycle assessment (OLCA): methodological issues and case studies in the beverage-packaging sector. In: Muthu SS (ed) Environmental footprints of packaging, 1st edn. Springer, Singapore

Manzardo A, Loss A, Jingzheng R, Zuliani F, Scipioni A (2018a) Definition and application of activity portfolio and control/ influence approaches in organizational life cycle assessment. J Clean Prod 184:264-273. https://doi.org/10.1016/j.jclepro.2018. 02.262
Manzardo A, Loss A, Niero M, Vianello C, Scipioni A (2018b) Organizational life cycle assessment. The introduction of the production allocation burden. Procedia CIRP 69:429-434. https://doi. org/10.1016/j.procir.2017.11.002

Martínez-Blanco J, Inaba A, Quiros A, Valdivia S, Milà-i-Canals L, Finkbeiner M (2015) Organizational LCA. The new member of the LCA family - introducing the UNEP/SETAC Life Cycle Initiative guidance document. Int J Life Cycle Assess 20(8):10451047. https://doi.org/10.1007/s11367-015-0912-9

Martínez-Blanco J, Inaba A, Finkbeiner M (2016) Life cycle assessment of organizations. In: Finkbeiner M (ed) Special types of life cycle assessment, LCA Compendium - The Complete World of Life Cycle Assessment. Springer, Dordrecht

Martínez-Blanco J, Forin S, Finkbeiner M (2018) Launch of a new report. "Road testing organizational life cycle assessment around the world: applications, experiences and lessons learned". Int J Life Cycle Assess 23(1):159-163. https://doi. org/10.1007/s11367-017-1409-5

Martínez-Blanco J, Forin S, Finkbeiner M (2019) Lessons learned from road testing the guidance on organizational life cycle assessment. Under review

Mazzi A, Toniolo S, Catto S, de Lorenzi V, Scipioni A (2017) The combination of an environmental management system and life cycle assessment at the territorial level. EIA Rev 63:59-71. https://doi. org/10.1016/j.eiar.2016.11.004

Mekonnen MM, Hoekstra AY (2012a) A global assessment of the water footprint of farm animal products. Ecosystems 15(3):401-415. https://doi.org/10.1007/s10021-011-9517-8

Mekonnen MM, Hoekstra AY (2012b) The blue water footprint of electricity from hydropower. Hydrol Earth Syst Sci 16(1):179-187. https://doi.org/10.5194/hess-16-179-2012

Mudd GM (2008) Sustainability reporting and water resources. A preliminary assessment of embodied water and sustainable mining. Mine Water Environ 27(3):136-144. https://doi.org/10.1007/s10230-0080037-5

Neppach S, Nunes KRA, Schebek L (2017) Organizational environmental footprint in German construction companies. J Clean Prod 142: 78-86. https://doi.org/10.1016/j.jclepro.2016.05.065

Northey SA, Haque N, Lovel R, Cooksey MA (2014) Evaluating the application of water footprint methods to primary metal production systems. Miner Eng 69:65-80. https://doi.org/10.1016/j.mineng. 2014.07.006

Pfister S, Bayer P (2014) Monthly water stress. Spatially and temporally explicit consumptive water footprint of global crop production. J Clean Prod 73:52-62. https://doi.org/10.1016/j.jclepro.2013.11.031

Pfister S, Scherer L (2015) Uncertainty analysis of the environmental sustainability of biofuels. Energy Sustain Soc 5(1):1105. https:// doi.org/10.1186/s13705-015-0058-4

Pfister S, Koehler A, Hellweg S (2009) Assessing the environmental impacts of freshwater consumption in LCA. Environ Sci Technol 43(11):4098-4104. https://doi.org/10.1021/es802423e

Stoessel F, Juraske R, Pfister S, Hellweg S (2012) Life cycle inventory and carbon and water FoodPrint of fruits and vegetables. Application to a Swiss retailer. Environ Sci Technol 46(6):32533262. https://doi.org/10.1021/es2030577

UN Environment (2017) Road testing organizational life cycle assessment around the world - Applications, experiences and lessons learned. Applications, experiences and lessons learned. United Nations Environment Programme, Paris

UNEP (2015) Guidance on organizational life cycle assessment. United Nations Environment Programme and Society for Environmental Toxicology and Chemistry, Paris

WBCSD/WRI (2004) The greenhouse gas protocol. A Corporate Accounting and Reporting Standard, Revised ed. World Resources Inst, Washington, DC 
Wiedmann T, Minx J (2007) A definition of 'carbon footprint'. In: Pertsova CC (ed) Ecological economics research trends. Nova Science Publ, New York, pp 1-11

Wiedmann TO, Schandl H, Lenzen M, Moran D, Suh S, West J, Kanemoto K (2015) The material footprint of nations. PNAS 112(20):6271-6276. https://doi.org/10.1073/pnas.1220362110
Zhang C, Anadon LD (2013) Life cycle water use of energy production and its environmental impacts in China. Environ Sci Technol 47(24):14459-14467. https://doi.org/10.1021/es402556x

Publisher's note Springer Nature remains neutral with regard to jurisdictional claims in published maps and institutional affiliations. 